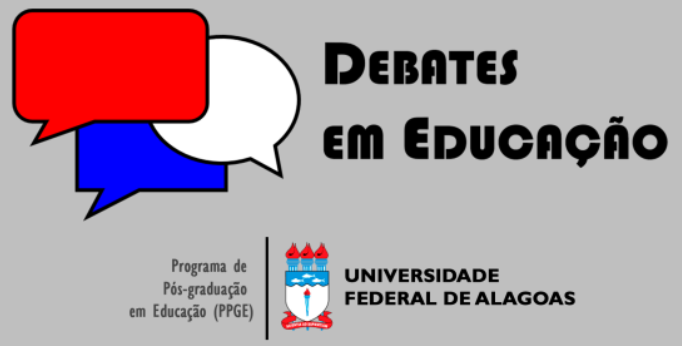

ISSN Eletrônico 2175-6600

Vol. I I | N. 25 | Set./Dez. | 2019

Cristiane Neves de Oliveira

9 iD

Universidade do Estado da Bahia (UNEB) cnoliveira@uneb.br

Sérgio Henrique Conceição

(9) iD

Universidade do Estado da Bahia (UNEB) shconceicao@uneb.br

\section{ASSISTÊNCIA FINANCEIRA FEDERAL NA EDUCAÇÃO SUPERIOR: A EXPERIÊNCIA DAS UNIVERSIDADES ESTADUAIS DA BAHIA}

\section{RESUMO}

Este texto tem por objetivo apresentar, a partir de uma investigação documental em perspectiva descritivo-exploratória, o cenário contemporâneo do financiamento da educação e a assistência financeira da União, no âmbito das políticas públicas voltadas ao ensino superior. $\bigcirc$ trabalho delimita a repercussão na gestão financeira das Universidades Estaduais da Bahia, a partir da análise dos marcos normativos que disciplinam essas práticas por meio de três eixos: Universidade e direito à educação pública, Financiamento Vinculado e Assistência Financeira da União. Os resultados evidenciam lacunas normativas e necessidade de aperfeiçoamento na definição das fontes de financiamento como premissas para a defesa da sustentabilidade financeira dessas instituições públicas de ensino superior.

Palavras-chave: Universidades Estaduais. Financiamento. Assistência Financeira da União.

\section{FEDERAL FINANCIAL ASSISTANCE IN HIGHER EDUCATION: THE EXPERIENCE OF THE STATE UNIVERSITIES OF BAHIA}

\begin{abstract}
This text aims to present, from a documental research in a descriptive-exploratory perspective, the contemporary scenario of the financing of education and the financial assistance of the Union in the scope of the public policies directed to higher education. The work delimits the repercussion in the financial management of the State Universities of Bahia, from the analysis of the normative frameworks that discipline these practices through three axes: University and the right to public education, Linked Financing and Union Financial Assistance. The results show normative gaps and the need to improve the definition of funding resources as premises for the defense of the financial sustainability of these public higher education institutions.
\end{abstract}

Keywords: State Universities. Financing. Financial Assistance of the Union.

Submetido em: 20/07/2019

Aceito em: 04/1 1/2019

Publicado em: 23/12/2019

d. http://dx.doi.org// 0.28998/2175-6600.2019v| In25p329-343 


\section{INTRODUÇÃO}

trabalho discute os mecanismos de assistência financeira preconizados no texto constitucional (BRASIL, 1988, caput art. 21I), os quais acessam as Universidades Estaduais, e, em especial, as Universidades Estaduais da Bahia (UEBA), no apoio a manutenção de suas atividades acadêmicas e científicas, considerando a missão universitária (ensino, pesquisa e extensão), os impactos sociais dessa atuação na contribuição para o desenvolvimento econômico e social no estado da Bahia (BARBOSA, 20 I3), e, seu protagonismo histórico, frente à ausência de oferta universitária federal no interior do estado baiano, por quase quatro décadas (FIALHO e CARNEIRO, 20I6).

Este trabalho tem como objetivo geral investigar acerca do arranjo normativo que marca o processo de assistência financeira federal a instituições de ensino superior, no âmbito da função constitucional supletiva da União, considerando o direito social de acesso a esse nível de ensino pelos cidadãos e as especificidades que pautaram sua constituição.

As universidades estaduais baianas enquanto instituições de ensino superior (IES), respondem por parcela significativa na oferta dessa modalidade educacional no estado da Bahia, $40 \%$ da oferta pública de ensino superior no estado, corresponde a instituições públicas de natureza administrativa autárquica não federal, que, consequentemente, vivenciam as tensões e limitações inseridas nesse arranjo (MOTA JÚNIOR e CONCEIÇÃO, 2016).

O esforço investigativo a partir de uma análise documental, subsidiada por contribuições de natureza bibliográfica apresenta elementos tanto para o debate acerca da sustentabilidade financeira das instituições estaduais de ensino superior, face à condição restritiva de financiamento estadual resultante do pacto federativo vigente (CONCEIÇÃO, 20 I6; FIALHO e CARNEIRO, 20 I6; MOTA JÚNIOR, 20I6) quanto do processo histórico de avanços e recuos das políticas educacionais no reconhecimento do direito social de acesso à educação superior pública.

Nesse sentido, o trabalho avalia os cenários das políticas públicas voltadas ao ensino superior, a partir da análise da Constituição Federal (CF), da Lei de Diretrizes e Bases da Educação (LDB) e das normas complementares que regulam os mecanismos de assistência financeira federal a instituições públicas de ensino superior não federais (BRASIL, 1988, 1996).

O texto apresenta considerações sobre o referido arranjo constitucional, político e normativo em vigor no campo da assistência financeira federal a instituições estaduais de ensino superior (não federais) e incompletudes normativas desse modelo bem como dos aspectos subjacentes ao financiamento vinculado ao poder público estadual.

Outrossim, o estudo evidencia os mecanismos de limitação financeira; a garantia do direito à educação, pautados em uma suposta racionalidade financeiro-orçamentária, tanto no âmbito federal 
quanto estadual que se efetivam no Brasil, a partir da década de 1990, com o recrudescimento do ideário neoliberal que prevê a redução dos investimentos públicos e da presença do estado como promotor de políticas de interesse público (NOGUEIRA, 2002).

Para alcance dos objetivos, o estudo, ora apresentado, fundamentou-se na interlocução com os aspectos constitucionais e contemporâneos da gestão financeira das Universidades Estaduais da Bahia, tratando-se, portanto, de um estudo exploratório-descritivo. Quanto ao delineamento, de forma geral, tanto a pesquisa documental como a bibliográfica foram utilizadas, a fim de subsidiar as análises.

Gil (2008, p. 28) salienta que "[...] há pesquisas que, embora definidas como descritivas, a partir de seus objetivos, acabam servindo mais para proporcionar uma nova visão do problema, o que as aproxima das pesquisas exploratórias". Desse modo, os pesquisadores sociais, frequentemente, utilizam as pesquisas descritivas juntamente com as exploratórias, pois se preocupam com uma atuação prática (GIL, 2008).

O trabalho está sistematizado a partir da presente introdução, seguida de uma revisão de literatura que explora aspectos relacionados à Universidade e o direito à educação superior pública, do Financiamento Vinculado e da Assistência Financeira da União; dos resultados da análise bibliográfica e documental na seção denominada Desdobramentos e consequências para as universidades estaduais e encerra-se com as considerações finais e recomendações da pesquisa.

\section{REVISÃO DE LITERATURA}

\section{I Universidade e Direito à Educação Pública}

A educação superior no Brasil passou a ser preocupação do Estado de forma tardia.

Conforme Fávero (2006), algumas tentativas de criação de universidades ocorreram sem êxito ainda durante o período monárquico e mesmo após a Proclamação da República ( 1889 ).

Apesar da Constituição de I89| ter mantido o ensino superior como atribuição do poder central, ainda que sem exclusividade, o surgimento da universidade, apoiado em ato do Governo Federal foi postergado sucessivamente, dando espaço para a criação de faculdades isoladas, que acabaram por deslocar, ainda que provisoriamente, a atribuição da órbita Federal para a dos Estados (FÁVERO, 2006).

Assim, as agregações das diversas instituições criadas nos estados deram origem à maioria das universidades brasileiras, federais e estaduais, o que acabou por confundir, historicamente, a oferta de ensino superior com a missão universitária (ensino, pesquisa e extensão).

À Universidade cabe o compromisso de garantir com efetividade o cumprimento das responsabilidades constitucionais, expressas nas ações finalistas de ensino, pesquisa e extensão. 
A Constituição Federal de 1988 (CF/I 988) trouxe, pela primeira vez, um artigo específico sobre a autonomia e os princípios norteadores das universidades. Nesse sentido, estabelece que: "as universidades gozam de autonomia didático-científica, administrativa e de gestão financeira e patrimonial, e obedecerão ao princípio de indissociabilidade entre ensino, pesquisa e extensão" (BRASIL, 1988, caput art. 207).

A CF/l 988 acolheu, ainda, a premissa da educação como função pública, como direito de todos e dever do Estado e da família (BRASIL, 1988, caput art.205).

A educação foi, durante a maior parte da história, um assunto de âmbito privado, e não do público. A ingerência do Estado nas questões de educação começa a ganhar vulto a partir do século dezoito, concomitante com a ideia do desenvolvimento de sistemas nacionais de educação, ligados aos processos político-sociais de consolidação dos Estados nacionais europeus, instâncias que culminaram com o sistema de instrução pública instalado com a Revolução Francesa e que se estenderia depois pelo mundo. (GALLO, 1988, pp.5-6).

De forma complementar, Alves (200I) ressalta que a efetiva universalização e o estabelecimento da educação escolar no mundo ocidental ocorreram apenas quando o desenvolvimento das forças produtivas e a acumulação do capital em nível mundial foram suficientes para financiar, através da arrecadação dos tributos, o investimento e os gastos públicos na construção dos sistemas escolares, podendo a partir de então falar da existência de um sistema escolar estatal, público, universal e gratuito.

Pode-se afirmar então, que foi necessário que o modo de produção capitalista alcançasse sua fase imperialista e monopolista para que o Estado contemporâneo, a partir da segunda metade do século XX, na condição de coadjuvante, parceiro e indutor privilegiado do capital, transferisse parte da renda social à construção, expansão e universalização da educação pública.

Desse modo, o ideário, a implantação e a universalização da educação no mundo contemporâneo, sob o apoio financeiro da instituição Estado e sob a declaração da função pública, foram frutos de uma necessidade do modo de produção capitalista e sua demanda pelo trabalho escolarizado e qualificado.

Outrossim, no que se refere à função pública da educação e o dever do Estado, mas especificamente no âmbito das universidades públicas, Santos assim discorre:

[...] enquanto a universidade e os seus serviços foram um inequívoco bem público que competia ao Estado assegurar, esta dependência não foi problemática, [...]. No momento, porém, em que o Estado, [...], decidiu reduzir o seu compromisso político com as universidades e com a educação em geral, convertendo esta num bem que,sendo público,não tem de ser exclusivamente assegurado pelo Estado, a universidade pública entrou automaticamente em crise institucional. Se esta existia antes, aprofundou-se. Pode-se dizer que nos últimos trinta anos a crise institucional da universidade na grande maioria dos países foi provocada ou induzida pela perda de prioridade do bem público universitário nas políticas públicas e pela consequente secagem financeira e descapitalização das universidades públicas. (SANTOS, 2008, pp. 7-8).

Pode-se destacar ainda, que a educação superior brasileira segue também os pressupostos da Lei n. 9.394 de 20 de dezembro de 1996, a Lei de Diretrizes e Bases da Educação (LDB), que por sua vez prevê a gratuidade do ensino público em estabelecimentos oficiais (BRASIL, 1996, art. 3², inciso VI, caput). 
Diante dessa compreensão normativa e histórica, pode-se concluir que a universidade brasileira, tardiamente constituída, é uma instituição que, salvo raras exceções, não surgiu de maneira planejada, de forma que a responsabilidade por seu financiamento ainda suscita muitos questionamentos.

Do mesmo modo, considerando-se que, a partir do final do século $X X$, as premissas de redução de papel do estado e indução da mercantilização da educação passam a ocupar protagonismo e do provável consenso de que no âmbito das políticas públicas tanto em escala local quanto global, Ihe negam apoio, a sobrevivência das instituições públicas de ensino superior, especialmente, as instituições não federais têm seu futuro ameaçado.

As universidades estaduais, implementadas a partir da ausência de oferta federal de ensino superior, especialmente, no interior do estado da Bahia, algo que se prolongou até o início do século $X X \mid$, vive, cotidianamente, em um cenário de incertezas e restrições, uma vez que são públicas, para responder à demanda de oferta superior, mas são não federais para acessar determinadas fontes de assistência financeira (FIALHO \& CARNEIRO, 20I6).

\subsection{Financiamento Vinculado}

A partir de 1960 e até a década de 1970, em virtude do intenso desenvolvimento do país, e para que fosse possível atender à crescente demanda por profissionais habilitados para o exercício da docência no sistema de ensino público estadual na Bahia, face à inequívoca omissão histórica de oferta federal de ensino superior, foram criadas as escolas de educação superior para formação de professores no interior do estado (BOAVENTURA, 2009).

A partir da agregação dessas escolas de formação, foram sendo estruturadas as quatro universidades que hoje compõem o sistema estadual de educação superior da Bahia. Duas delas estão estruturadas no sistema multicampi: a Universidade do Estado da Bahia (UNEB) e a Universidade Estadual do Sudoeste da Bahia (UESB). As outras duas, unicampi, a Universidade Estadual de Feira de Santana (UEFS) e a Universidade Estadual de Santa Cruz (UESC).

O protagonismo da oferta de educação superior pelas Universidades Estaduais da Bahia (UEBA), especialmente, em municípios interioranos no estado, ratifica uma condição nacional do fenômeno, onde a resposta à demanda da sociedade por educação superior foi, inicialmente, equacionada com as iniciativas estaduais, tais como os exemplos do Paraná e Minas Gerais (FIALHO \& CARNEIRO, 20 I6).

As universidades públicas estaduais baianas estão inseridas na estrutura administrativa do Estado e vinculadas à Secretaria de Educação do Estado. A Constituição do Estado da Bahia (CE/BA) determina a responsabilidade do estado pela manutenção financeira integral dessas instituições de ensino superior (BAHIA, 1989, art. 262, caput). 
Essas universidades têm um relevante papel na interiorização da educação superior pública no estado da Bahia, já que respondem por $40 \%$ da oferta de ensino superior público no estado, por meio da realização de atividades relacionadas ao ensino, à pesquisa e a extensão (MOTA JÚNIOR, 20 l6).

Do mesmo modo, as universidades estaduais baianas contribuem para o desenvolvimento econômico e sociopolítico de diversos territórios, como agentes protagonistas na ampliação da oferta de profissionais de nível superior no estado, atuando sem a presença de oferta federal, no interior do estado, por pelo menos 40 anos. (FIALHO e CARNEIRO, 20l6; MOTA JÚNIOR, 20I6; BARBOSA, 20I3).

A gestão dessas instituições é compreendida, fundamentalmente, a partir das determinações e finalidades legais da educação superior no país, das especificidades da legislação estadual e dos limites operacionais da conjuntura econômico-orçamentária do Estado da Bahia.

Nesse sentido, compreende-se que a manutenção e expansão dessas universidades demandam um crescimento proporcional do financiamento, de forma a contemplar, tanto a dimensão de sua estrutura física, corpo docente e técnico-administrativo, como a dimensão de assistência estudantil na perspectiva de apoio ao acesso e permanência.

contexto financeiro de um estado nordestino, a equivocada compreensão de que a oferta de educação superior pública é de responsabilidade exclusiva federal (BRASIL, 1988, art. 21 I, § I, caput) e, o desconhecimento de que essa atividade foi exercida em caráter público durante 40 anos, quase que exclusivamente pelas UEBA constituem desafios a serem enfrentados.

A necessidade de assistência financeira que garanta a manutenção das UEBA, portanto, deve considerar a defesa do patrimônio investido ao longo desse tempo, seu papel de redutor das desigualdades sociais locais e seu protagonismo histórico.

A compreensão do atual cenário do financiamento dessas instituições estaduais de ensino superior é pontuada por Barbosa (2013, p. 70-7I), como uma dinâmica que "segue um procedimento extremamente burocrático. A Secretaria do Planejamento do Estado da Bahia (SEPLAN-BA) realiza estimativas de receita e define os tetos orçamentários das setoriais, neste caso, da Secretaria de Educação". Esta Secretaria, então, segundo o referido autor (idem), "define as cotas orçamentárias para as universidades estaduais, em conformidade com a distribuição relativa estabelecida pelo Fórum dos Reitores".

Ainda segundo Barbosa (ibidem), no financiamento do ensino superior da Bahia predominam características do modelo incremental.

Para Velloso (2000, p. 48), "um orçamento incremental ocorre quando a definição dos montantes de recursos a serem alocados para os programas, ações, órgãos ou despesas se realiza mediante incorporação de acréscimos marginais em cada item de despesa, mantendo-se o mesmo conjunto de despesas do orçamento anterior (ou com pequenos ajustes". 
Dessa forma, as opções e prioridades estabelecidas no passado tendem a permanecer inalteradas ao longo do tempo e o orçamento termina não refletindo uma reavaliação quanto às novas necessidades e prioridades da sociedade.

Com efeito, Miranda (2013, p. 202) relata que no período de 2004 a 2013 o orçamento destinado às Universidades Estaduais da Bahia (UEBA) se manteve linear, com predominância absoluta de despesas correntes e, mais especificamente, de despesas com pessoal e encargos, com baixa capacidade de investimentos.

Nesse período, essas instituições ampliaram sua atuação seja na oferta de vagas na graduação seja na pós-graduação, inclusive, com implantação de novos programas de pós-graduação (doutorados e mestrados), ampliação dos números de projetos de pesquisa, programas de extensão e assistência estudantil, sem, contudo, receber novo alinhamento no patamar de investimento.

Nesse contexto, para que as atividades de extensão, pesquisa científica e tecnológica, não sofram descontinuidade, a gestão universitária recorre constantemente à captação de recursos externos, cenário em que a assistência financeira da União ganha relevância (BRASIL, 1988, art. 21 I, § I, caput).

Convém destacar, que o elevado senso de responsabilidade e missão do corpo docente, técnicoadministrativo e discente tem levado essas universidades a alcançarem um nível de desempenho e excelência, apesar das adversidades do contexto econômico-orçamentário.

Mota Júnior (2016) destaca, ainda, que as Universidades Estaduais da Bahia, atualmente, têm enfrentado limitações financeiras, em consequência de determinações de Decretos Estaduais que limitam os gastos públicos, afetando diretamente a autonomia administrativa dessas instituições, impedindo o cumprimento de seus objetivos institucionais ou diminuindo a qualidade dos serviços prestados à sociedade.

Dessa forma, cabe ao ente federativo, responsável pelo financiamento integral dessas universidades, definir o nível adequado de recursos financeiros alocados, de forma que a autonomia constitucional possa ser exercida e os recursos alocados reflitam as necessidades e prioridades institucionais.

Nesse cenário, faz-se necessário compreender a universidade pública por uma ótica do investimento sociopolítico, isto é, considerando a educação, efetivamente, como um esforço financeiro garantidor de um direito social, ao invés, de privilégio ou serviço. (CHAUí, 2003).

Essa compreensão, entretanto, está cada vez menos presente nas práticas das políticas estatais, cuja compreensão hegemônica do interesse do capital e da negação dos direitos sociais, frequentemente, pautam, em sentido contrário, a agenda das políticas públicas (CHAUÍ, 2003). 
Nesse sentido, a Emenda Constitucional n 95 de 15 de dezembro de 2016 que prevê "congelamento" de investimentos públicos, inclusive para as áreas sociais, especialmente, educação, parece ratificar a percepção da prevalência dos interesses do capital.

Assim, como em períodos ditatoriais vivenciados no país, que, similarmente, suprimiu vinculações constitucionais de recursos para educação, a referida emenda constitucional, sonega à educação condições materiais que, eventualmente, possam oferecer subsídios à manutenção dos sistemas públicos de ensino superior, federais e não federais (PINTO, 2000; CONCEIÇÃO, 2016).

Do mesmo modo, convém destacar que, se a universidade tem um compromisso com a sociedade, de igual maneira o Estado deve assumir plenamente o dever constitucional e o compromisso social com a manutenção de suas atividades, através do cumprimento das determinações constitucionais voltadas à garantia dos direitos sociais.

\subsection{Assistência Financeira da União}

A Constituição Federal de 1988 elenca as competências comuns da União, Estados, Municípios e Distrito Federal e ressalta em seu parágrafo único que, por lei complementar, serão fixadas normas para cooperação entre os entes, tendo em vista o equilíbrio do desenvolvimento e do bem-estar nacional (BRASIL, 1988, art. 23, caput).

Nesse sentido, a CF/I 988 destaca a responsabilidade da União de assistir técnica e financeiramente a estados e municípios, em função redistributiva e supletiva, para a garantia de equidade e de padrão mínimo de qualidade na oferta educacional. (BRASIL, 1988, art. 21 I, caput).

Na tipologia de assistência financeira da União à educação, encontra-se, a seguinte diferenciação: a assistência compulsória e a assistência voluntária.

A primeira, chamada oficialmente de constitucional legal, diz respeito a ações inscritas na Constituição da República ou na legislação, por exemplo, a complementação da União ao Fundo de Manutenção e Desenvolvimento de Educação Básica e de Valorização dos Profissionais da Educação (FUNDEB).

Por sua vez, a assistência voluntária compreende ações não prescritas na legislação, as quais, na atualidade, são muitas e variadas, desde, por exemplo, programas de formação inicial ou continuada de profissionais da educação a repasses de recursos para a construção de escolas (FARENZENA, 20I2, p. 108).

De acordo com a Lei de Responsabilidade Fiscal (LRF), transferência voluntária é " [... ] a entrega de recursos correntes ou de capital a outro ente da Federação, a título de cooperação, auxílio ou assistência 
financeira, que não decorra de determinação constitucional, legal ou os destinados ao Sistema Único de Saúde" (BRASIL, 2000, art. 25 ,caput).

Sendo de natureza voluntária, as transferências de recursos financeiros da União para as Universidades Estaduais, formalizadas mais comumente mediante convênios, ocorrem normalmente em decorrência da aprovação de projetos dessas instituições, em editais e programas especiais de apoio à capacitação, expansão e modernização da infraestrutura, projetos de extensão ou por intermédio de emendas de parlamentares ao Orçamento Geral da União.

Por serem constituídas como autarquias estaduais, as Universidades Estaduais Baianas gozam de autonomia administrativa, conforme prevê a Constituição do Estado da Bahia, que, entre outras prerrogativas, Ihes permite celebrar acordos, convênios, contratos e outros instrumentos congêneres para atender às suas finalidades (BAHIA, 1989, caput art. 262, §1%).

Destaque-se que a não regulamentação da instância federativa preconizada no Plano Nacional de Educação 20|4-2024 (BRASIL, 20|4) evidencia lacuna na cooperação federativa, especialmente, em matéria de educação superior, e, consequentemente, ratificam sérias limitações à sustentabilidade financeira das instituições estaduais de ensino superior mesmo quando percebidas sua relevância e protagonismo histórico.

Convém destacar, entretanto, que o cenário de cooperação financeira entre as UEBA, instâncias estaduais, com o governo federal, sem dúvida, apresentou avanços desde a promulgação da Constituição de 1988, por meio da criação e aperfeiçoamento de mecanismos para efetivação e controle das transferências voluntárias.

Outrossim, apesar da regulamentação das práticas e aperfeiçoamento dos instrumentos jurídicos envolvidos, permanece o desafio de desvencilhar a assistência financeira federal às UEBA dos interesses político-partidários transitórios (OLIVEIRA, 2017).

\section{RESULTADOS DO ESTUDO: DESDOBRAMENTOS E CONSEQUÊNCIAS PARA AS UNIVERSIDADES ESTADUAIS BAIANAS}

De forma objetiva e rigorosa, podemos inferir que o financiamento das universidades estaduais no Brasil, partindo dos pressupostos constitucionais, está assegurado de "forma integral" pelas respectivas administrações públicas estaduais, sendo a atuação da União feita por meio da assistência técnica e financeira aos entes federados (BRASIL, 1988, art. 212, caput).

Para compreender o papel do governo estadual e o da União no financiamento da educação superior, é necessário compreender o panorama das responsabilidades governamentais no âmbito da educação superior. 
A oferta pública da educação superior no Brasil é historicamente descentralizada. Inicialmente, por uma inserção tardia das instituições universitárias no Brasil, já na metade do século $X X$, constituídas a partir da aglutinação de instituições estaduais preexistentes, notadamente, implantadas nas capitais do Brasil, e, posteriormente, pela baixa adesão das políticas públicas voltadas à educação superior pública no país.

A promulgação da Constituição Federal de 1988 ratificou a compreensão da educação e da educação superior, como direito social de caráter gratuito, de qualidade e financiado parcialmente pelo estado. Posteriormente, a partir da década de 2000, foi induzida a expansão da oferta de ensino superior privado.

A transição das políticas educacionais nessas três décadas, especialmente, em relação à oferta de educação superior pública, refletiu a transfiguração dessas políticas, do sentido estatal para a dimensão empresarial mercantilista. $\bigcirc$ caráter mercantil que pautou fortemente a década de 1990 foi mitigado com a "virada estatal" na década de 2000 e ressurgiu neoliberal na década de 2010, dado a "renovada" compreensão do ideário de redução do papel do estado na garantia dos direitos sociais.

A agenda atual de compreensão do estado mínimo e de suposta racionalidade fiscal-orçamentária coloca a educação como elemento secundário no contexto das políticas públicas nacionais, o que representa desafios e riscos à construção de uma sociedade socialmente responsável, próspera e igualitária.

Apesar disso, sobrevivem, em contexto adverso de financiamento, as instituições estaduais de ensino superior, tais como, as universidades estaduais da Bahia (UEBA), em sua missão de oferta de ensino, pesquisa e extensão.

De um lado, pressionadas por condições limitantes de financiamento público local ou por mecanismos de interferência a sua autonomia universitária e, do outro lado, pelos mecanismos de assistência financeira da União (convênios, programas e emendas parlamentares) que, se por um período, com o advento da Constituição Federal de 1988, apresentou significativa expansão, atualmente, vivenciam estrangulamento imposto pela suposta racionalidade fiscal orçamentária, renovada pelo neoliberalismo hegemônico.

A responsabilidade do financiamento educacional pelos entes federativos, de acordo com o texto constitucional, é exercida, preliminarmente, pela aplicação dos percentuais mínimos de investimento sobre as receitas arrecadadas com impostos (BRASIL, 1988, caput art. 212), e, subsidiariamente, pela cooperação federativa voluntária entre os entes estatais.

Os recursos vinculados à educação devem ser distribuídos para todos os níveis do sistema de ensino, tendo os entes federativos (municípios e estados) a responsabilidade de assegurar prioridade ao atendimento das necessidades do ensino básico e a União pelo ensino superior.

Nesse sentido, a prioridade na aplicação desses recursos públicos é direcionada à universalização da educação básica, garantia do seu padrão de qualidade e equidade, de oferta obrigatória e gratuita dos 4 
(quatro) aos 17 (dezessete) anos de idade, assegurada, inclusive, sua oferta gratuita para todos que a ela não tiveram acesso na idade própria. (BRASIL, 1988, art. $212, \S 3^{\circ}$, caput).

No que diz respeito ao ensino superior, ou seja, "acesso aos níveis mais elevados de ensino, da pesquisa e da criação artística", será efetivado segundo a capacidade de cada ente federativo (BRASIL, 1988, caput art. 208).

AAssistência Financeira da União a Estados e Municípios, em matéria de educação superior, ocorre de forma voluntária, e, especialmente, para o estado da Bahia a constituição assegura a responsabilidade do poder local pela manutenção integral das universidades (BAHIA, 1989).

De outro modo, o volume dos recursos destinados às universidades pelo poder público estadual tem se mostrado aquém da função universitária, que envolve ensino, pesquisa e extensão, e, ainda, sofrido frequentes contingenciamentos (MOTA JÚNIOR, 2016).

Percebe-se que existem lacunas na articulação federativa, no campo da educação, se considerado que a assistência financeira para a educação superior é voluntária, ou seja, sem obrigatoriedade e sem definição de percentuais mínimos e dependentes de articulação político-partidárias, o que resulta em investimentos públicos em educação superior, por vezes, aquém de suas demandas e propósitos (OCDE, $2011)$.

Ressalta-se ainda, a frágil premissa constitucional baiana, no sentido de ratificar a condição de responsabilidade integral de financiamento da educação superior pelo estado local, ignorando o dispositivo constitucional federal acerca da assistência financeira, mesmo que voluntária, da União.

Nesse cenário, não se encontra devidamente compreendido, o protagonismo estadual, que assim como ocorrido em outros estados, Paraná, Minhas Gerais, e, mesmo São Paulo, foram estados pautados a responder, mesmo em contexto econômico desfavorável, pela omissão histórica de oferta federal de ensino superior, no estado da Bahia, restrita a capital do estado até a metade da primeira década do século $X X I$.

trabalho infere quanto à necessidade de aperfeiçoamento das práticas político-administrativas dos instrumentos de assistência financeira da União (convênios, programas e emendas parlamentares) voltadas às universidades estaduais, às universidades estaduais baianas e demais instituições estaduais de ensino superior.

O processo evolutivo das políticas públicas voltadas ao financiamento da oferta de educação pública superior deve fazer efetivar, o necessário protagonismo financeiro da União e a efetivação da função supletiva constitucional.

Um processo de intervenção e aperfeiçoamento da política de financiamento de educação superior pública, precisa, possivelmente, efetivar um fundo compensatório dos investimentos públicos estaduais em educação superior. 
Os aportes de recursos federais, resultantes da execução desse fundo, constituirão contrapartida dos investimentos públicos estaduais realizados, que entes mais pobres, especialmente, a Bahia, se viram induzidas a exercer, em função da ausência de oferta federal de educação superior.

A busca por garantir a oferta e o acesso ao direito social de educação pública e a oferta de educação pública superior, especificamente, torna-se diretriz relevante para a construção de um caminho de desenvolvimento socioeconômico, técnico e científico para o país.

Essas políticas públicas, adequadamente articuladas, serão, possivelmente, capazes de contribuir para a superação do papel periférico, que o modelo de capitalismo global tem nos imposto desde o século $X V$, de agroexportador industrial, para o qual estaremos condenados se não estivermos dispostos a enfrentar (MONLEVADE, 200I).

De outro modo, cabe a às instituições estaduais de ensino superior, notadamente, as universidades estaduais baianas, objeto do presente estudo, desenvolver e efetivar mecanismos que propiciem efetividade, eficácia, eficiência e relevância quanto à destinação e execução dos recursos públicos através dos mecanismos de assistência financeira federal (OLIVEIRA, 20।7; DAMÁSIO, 20 I7).

\section{CONSIDERAÇÕES FINAIS E RECOMENDAÇÕES DE ESTUDO}

As reflexões suscitadas por este estudo demonstraram que o cenário educacional se apresenta de forma desafiadora à gestão universitária das instituições públicas de ensino superior não federais, notadamente, pelo arranjo normativo do financiamento da educação superior e das limitações orçamentárias do poder público local.

A experiência da Bahia, que não difere de outros estados brasileiros, dada a omissão histórica de oferta federal de educação pública superior, constituíram sistemas estaduais de educação superior.

De outro modo, para que se possa assegurar a manutenção e o respeito ao patrimônio público investido, bem como a manutenção das atividades dessas instituições de ensino superior público, é necessária uma efetivação do regime de cooperação entre União e Estados, de forma que os mecanismos de assistência financeira da União possam contribuir significantemente para preservar o exercício de suas missões universitárias, conforme já preconizam o Plano Nacional de Educação 20 I 4-2024 (BRASIL, 20 I 4) e o texto constitucional (BRASIL, 1988)

Essa providência torna-se imperiosa, uma vez que o imobilismo político que demarca os últimos 5 anos da política nacional, o reposicionamento quanto à compreensão do estado mínimo, em matérias voltadas a garantia de direitos sociais, os contingenciamentos orçamentários e as desvinculações constitucionais parecem eleger a garantida do direito à educação pública como vítima prioritária da suposta racionalidade fiscal-orçamentária. 
Os sistemas estaduais de educação superior que foram constituídos, evidenciam que o protagonismo assumido pelos entes federativos locais, via de regra, buscou compensar a omissão histórica de oferta federal de educação superior pública.

De outro modo, encontram desafios relacionados à limitada capacidade de financiamento desses entes locais, as imprecisões normativo-administrativas de suas personalidades jurídicas não federais, que somados aos reduzidos mecanismos atuais de assistência financeira, parecem não dar conta da demanda pela manutenção das atividades de ensino, pesquisa e extensão dessas instituições.

Por fim, importa considerar que o regime de cooperação tem sido construído de forma gradual ao longo dos anos, e, diante da abrangência e importância das universidades estaduais, enquanto agentes de desenvolvimento, especialmente, no Estado da Bahia, tem-se tornado cada vez mais premente uma intervenção política mais efetiva.

A revisão das normas de financiamento dessas instituições, a constituição de fundo federal compensatório dos investimentos estaduais já realizados e em curso, são sugeridas pelo presente trabalho bem como a elaboração de futuras pesquisas que possam contribuir na superação das incompletudes, tanto políticas, jurídicas ou técnicas, capazes de superar os desafios identificados e garantir a continuidade dessas relevantes instituições públicas de ensino superior.

\section{REFERÊNCIAS}

ALVES, Gilberto L. A produção da escola pública contemporânea. 4.ed. Campinas, SP: Autores Associados, 2001.

BAHIA. Constituição ( 1989). Constituição do Estado da Bahia, Salvador, BA,05 out. 1989.Disponível em: http://www2.senado.leg.br/bdsf/bitstream/handle/id/70433/CE Bahia.pdf. Acesso em: 05 mai. 2019.

BARBOSA, C. Financiamento Público das Universidades Estaduais Baianas: restrições orçamentárias, expansão universitária e desenvolvimento local. 20 I3. 165 f. Tese (Doutorado em Educação) Programa de Pós-Graduação em Educação e Contemporaneidade, Departamento de Educação, Universidade do Estado da Bahia, Salvador, 2013. Disponível em: http://www.cdi.Uneb.br/pdfs/teses/2013/I I09|41328.pdf. Acesso em: 05 mai. 2019.

BOAVENTURA, E. M. A construção da universidade baiana: origens, missões e afrodescendência. Salvador: Edufba, 2009.

BRASIL. Constituição (1998). Constituição da República Federativa do Brasil. Brasília, DF: Senado Federal, 1988. Disponível em: http://www.planalto.gov.br/ccivil 03/Constituicao/Constituicao.htm. Acesso em: 05 mai. 2019.

BRASIL. Lei Complementar n. I0 I, de 4 de maio de 2000. Lei de Responsabilidade Fiscal. Estabelece normas de finanças públicas voltadas para a responsabilidade na gestão fiscal e dá outras providências.

Diário Oficial [da] República Federativa do Brasil, Brasília, DF, 05 maio 2000, Seção I, p. I. 
BRASIL. Lei de Diretrizes e Bases da Educação n. 9.394, de 20 de dezembro de 1996. Estabelece as diretrizes e bases da educação nacional. Diário Oficial [da] República Federativa do Brasil, Brasília, DF, 23 dez. 1996. Seção I. Disponível em: http://www.planalto.gov.br/ccivil 03/LEIS/19394.htm. Acesso em: 05 mai. 2019.

BRASIL. Emenda Constitucional n 95. Altera Ato das Disposições Constitucionais Transitórias, para instituir o novo Regime Fiscal, e dá outras providências. 15 de dez. Diário Oficial [da] República Federativa do Brasil, Brasília, 15/I2/2016. Disponível em: www.planalto.gov.br/ccivil 03/constituicao/Emendas/Emc/emc95.htm. Acesso em: 05 mai. 2019.

BRASIL. 2014. Lei n. 13.005. Aprova o Plano Nacional de Educação e dá outras providências (PNE 20 | 4-2024). 25 de jun. Diário Oficial da União, Brasília, 26/06/20 I 4 - Edição Extra. Disponível em: http://www.planalto.gov.br/ccivil_03/_ato20 II-20I4/20I4/lei/I3005.htm. Acesso em: 05 mai. 2019.

CONCEIÇÃO, S.H. 20 I6. Perspectivas e Desafios do Plano Nacional de Educação (PNE) (20|4-2024) no Contexto do Financiamento da Educação Básica. Educação em Revista, I7( I), p. 35-54.

CHAUÍ, Marilena. A universidade pública sob nova perspectiva. Revista Brasileira de Educação, Rio de Janeiro, n. 24, set./dez. 2003. Disponível em: http://www.scielo.br/pdf/rbedu/n24/n24a02.pdf. Acesso em: 05 mai. 2019.

DAMÁSIO, A.B. Fontes externas de financiamento: planejamento, gestão e multicampia no âmbito da Universidade do Estado da Bahia. Relatório Técnico (Mestrado Profissional). Universidade do Estado da Bahia (UNEB): Salvador, 20 I7. 124f.

FARENZENA, N. A assistência financeira da União às políticas educacionais locais. Revista Retratos da Escola, Brasília, v.6, n. I0, p. I05-1 17, 2008. Disponível em: http://www.esforce.org.br/index.php/semestral/article/view/I73/330. Acesso em: 05 mai. 2019.

FÁVERO, M. L. A. A Universidade no Brasil: das origens à Reforma Universitária de 1968. Educar. Curitiba, n.28. Editora UFPR. 2006.

FIALHO, N. H; CARNEIRO, B. P. B. Universidades estaduais e financiamento da educação superior: notas sobre os paradoxos, relevância e sustentabilidade. In: Universidades estaduais e financiamento da educação superior na Bahia. Nadia Hage Fialho (Org.). Salvador: Eduneb, 2016.

GALLO, S., A Educação Pública como Função do Estado. São Paulo, SP: 1988.

GIL, Antonio Carlos. Métodos e técnicas de pesquisa social. 6. ed. São Paulo: Atlas, 2008.

MIRANDA, M. R. F. A. Investimentos públicos diretos em educação superior na Bahia: um estudo de caso sobre o sistema estadual de educação superior da Bahia. 20 13. 229f. Dissertação (Mestrado em Gestão e Tecnologias Aplicadas) - Gestec, Universidade Estadual da Bahia, Salvador, 20 I3. Disponível em: http://www.uneb.br/gestec/files/20 13/06/Disserta\%C3\%A7\%C3\%A3o-de-Marta-Rosa-Farias-deAlmeida.pdf. Acesso em: 05 mai. 2019.

MOTA JÚNIOR, A. M. Política de financiamento para as Universidades Estaduais Baianas: dimensões relevantes à compreensão das demandas por recursos públicos na Universidade Estadual de Feira de Santana (UEFS). Relatório Técnico (Mestrado Profissional). Universidade do Estado da Bahia (UNEB): Salvador, 2017. I6 If. 
MOTA JÚNIOR, A. M.; CONCEIÇÃO, S. H. Política de financiamento das universidades estaduais baianas: desafios e reflexões. In: Universidades estaduais e financiamento da educação superior na Bahia. Nadia Hage Fialho (Org.). Salvador: Eduneb, 2016.

MONLEVADE, J. Educação pública no Brasil: contos \& descontos. Ceilândia-DF: Idea, 2. edição, 200 I.

NOGUEIRA, M. A. Administrar e dirigir: algumas questões sobre a escola, a educação e a cidadania. In: Políticas e gestão da educação: dois olhares. Lourdes Marcelino Machado e Naura Syria Carapeto Ferreira (Orgs.). Rio de Janeiro: DP\&A, 2002, p. 17-32.

OLIVEIRA, C.N. Fontes complementares de financiamento em universidades públicas: análise da gestão de convênios federais em uma universidade estadual, multicampi e multiregional. Relatório Técnico (Mestrado Profissional). Universidade do Estado da Bahia (UNEB): Salvador, 20 I7. 966.

SANTOS, Boaventura de Souza. A universidade no século XXI: para uma reforma democrática e emancipatória da universidade. 2. ed. São Paulo: Cortez, 2005.

VELLOSO, J. Universidade na América Latina: rumos do financiamento. Caderno de Pesquisa, São Paulo, n. I I 0, p. 39-66, 2000. Disponível em: http://www.scielo.br/pdf/cp/n I I0/n I | 0a02.pdf. Acesso em: 05 mai. 2019. 